\title{
LAS MUJERES RELIGIOSAS Y LAS GUERRAS CIVILES: LOS INICIOS DE LA ATENCIÓN HUMANITARIA EN COLOMBIA
}

\section{Religious women and civil wars in Colombia. The beginnings of humanitarian care}

\author{
Beatriz Castro Carvajal \\ Universidad del Valle, Cali, Colombia
}

\begin{abstract}
Resumen: A los tres años de la llegada a Bogotá de las primeras mujeres religiosas de la congregación francesa de vida activa Hermanas de la Caridad de la Presentación, se desencadenó la guerra civil de 1876. Las Hermanas se ofrecieron a auxiliar a los heridos de los combates y, a partir de esa iniciativa, siguieron atendiendo los heridos en las siguientes guerras civiles y en la guerra colombo-peruana, en 1933, por solicitud de los gobiernos. Sobre estas actividades dejaron registros escritos en cartas, diarios y otros documentos que nos permitirán presentar sus experiencias en la introducción de la atención humanitaria en Colombia, así como en la formalización de este servicio.
\end{abstract}

Palabras claves: congregaciones femeninas de vida activa, atención humanitaria, guerras, Colombia.

\begin{abstract}
Three years after the arrival in Bogotá of the first religious women of the French congregation of active life, the Sisters of Charity of the Presentation, the civil war of 1876 broke out. The Sisters offered themselves as assistants to those wounded in the fighting. Based on this initiative, they continued caring for the wounded in the following civil wars and in the Colombian-Peruvian war of 1933, at the request of the government. They left written records on these activities in letters, diaries, and other documents that allow us to present their experiences in the introduction of humanitarian care in Colombia, as well as its formalization.
\end{abstract}

Keywords: active life women's congregation, humanitarian care, wars, Colombia. 


\section{A modo de introducción}

Pasados tres años de la llegada de las primeras mujeres religiosas de la Congregación de las Hermanas de la Caridad de la Presentación ${ }^{1}$ a administrar, mediante contrato, el Hospital de San Juan de Dios de Bogotá, y meses después del arribo de las primeras hermanas de las misma congregación a Barranquilla y Medellín también para la administración de los hospitales de estas ciudades, se desencadenó la guerra civil de $1876 . .^{2}$ En septiembre de ese año hubo un combate entre los cerros de Monserrate y Guadalupe en las inmediaciones de Bogotá; las hermanas y toda la población de la capital escucharon disparos y al día siguiente corrió el rumor de que había muchos heridos. Según el relato de la Congregación, algunas de las hermanas que estaban a cargo del Hospital de San Juan de Dios de Bogotá, después de hablar y consultar con el Síndico de la institución, se desplazaron escoltadas por soldados al sitio del combate para auxiliar a los heridos. ${ }^{3}$

Tras esta iniciativa de la Congregación, en ese mismo mes el Gobierno les solicitó formalmente la atención de los heridos y les presentó la propuesta también de la administración del Hospital Militar de la capital. En octubre se firmó un contrato provisional, ante la urgencia y la imposibilidad de tener comunicación inmediata con la Casa Principal de la Congregación en Tours, para la autorización. Se acordó que seis hermanas empezaran a trabajar en la institución con la superiora hermana Anatolie para asistir a los heridos y enfermos, que fueron alrededor de doscientos durante la guerra civil. El contrato formal se firmó tres años después, en enero de 1879. ${ }^{4}$ La Congregación de las Hermanas de la Caridad de la Presentación, como las otras comunidades religiosas femeninas

1. La congregación femenina francesa Hermanas de la Caridad de la Presentación llegó a Bogotá en 1873 por solicitud de la Junta General de Beneficencia de Cundinamarca para administrar, con un contrato legalmente establecido, el hospital más grande de la ciudad, el de San Juan de Dios. Esta comunidad se enmarcaba dentro del surgimiento y consolidación de un nuevo modelo de congregaciones religiosas en Francia: no se trataba de monjas bajo la vieja y conocida forma de mujeres que hacían votos solemnes y que vivían en claustro, sino que, en este nuevo período, las hermanas eran mujeres religiosas que tomaban «votos simples», se formaban en seminarios y vivían en casas dirigidas por una hermana superiora, sin ningún tipo de voto de clausura. En el siglo XIX este modelo de organización religiosa se volvió más flexible, dado que adquirió cierta independencia de la jerarquía eclesiástica tradicional, lo que les permitió el despliegue de actividades de asistencia social como maestras, enfermeras y visitadoras, así como la administración de diversas instituciones (hospitales, asilos, orfanatos, escuelas y residencias para ancianos) en diferentes partes de Francia, con contratos con el Estado. Y además obtuvieron licencia de la Iglesia católica para hacer misiones (actividad restringida hasta entonces a las comunidades religiosas masculinas), hecho que les permitió expandirse por el mundo (Langlois, 1984).

2. La primordial razón de la guerra civil de 1876 fue un enfrentamiento acerca del rol del Estado y de la Iglesia católica en la educación, principalmente en las escuelas. Durante el siglo XIX en Colombia se desencadenaron nueve guerras civiles. La última fue la de los Mil Días (1899-1902) que fue la más larga y que se extendió por casi todo el territorio nacional.

3. Carta de la hermana Gertrudis a la reverenda madre Du Calvaire, Bogotá, 16 de enero de 1877. Archivo de la Congregación de las Hermanas de la Caridad Dominicas de la Presentación, Provincia de Bogotá (ACHCDPB).

4. Carta de la hermana Anatolie a la reverenda madre Du Calvaire, Bogotá, 14 de abril de 1877 , ACHCDPB. Este contrato permaneció vigente hasta 1920, cuando la congregación entregó la admi- 
hospitalarias francesas, tenía ya una amplia experiencia en esta «prestación de servicios» en Francia y otros países europeos y, por lo tanto, también conocimiento tanto sobre el tipo de contrato que podían firmar, como sobre los compromisos que podían asumir. El primer contrato establecido entre la Congregación y la Junta General de Cundinamarca siguió en gran parte el modelo de acuerdos que la comunidad religiosa de las Hijas de la Caridad de San Vicente de Paúl estableció para realizar sus actividades hospitalarias en Francia a partir del siglo XVII. ${ }^{5}$ Esta relación contractual entre la Congregación de la Hermanas de la Caridad de la Presentación y la Junta General de Beneficencia de Cundinamarca servirá de modelo para la administración de las instituciones de asistencia social del Estado colombiano por parte de congregaciones religiosas femeninas hasta alrededor de 1960 (Castro Carvajal, 2014a).

Asimismo, y aún más importante, la congregación, sin tiempo de consultar a la Casa Principal, pero sí con la aprobación del obispo, acordó con el Ministerio de Guerra, por primera vez, una colaboración para la atención humanitaria de los heridos y enfermos en la guerra civil de 1876, actividad que se desarrolló en Bogotá, Manizales, Medellín, Honda, Mariquita y Guayabal. Aunque se hace mención de contratos entre el Gobierno y la Congregación para el servicio en las Ilamadas «ambulancias» - que fueron campamentos itinerantes en los campos de batalla para la atención humanitaria de heridos y enfermos de los enfrentamientos bélicos -, no conocemos efectivamente, hasta ahora, ningún documento de este tipo, pero sí las cartas de diferentes generales o de distintos gobiernos que recogen la solicitud del servicio a las Hermanas, después de que los partidos políticos o los varios gobiernos por decreto tomaban la decisión de crear las mencionadas ambulancias. En noviembre de 1876 a la hermana Pauline le llegó una carta del Gobierno donde le manifestaban el deseo de que las hermanas fueran a la ambulancia de Tolima a cuidar a los heridos. ${ }^{6}$ En enero de 1877 la hermana Octavia recibió en Medellín una carta del secretario de Gobierno en la que este le informa de que en la ciudad de Manizales había un número

nistración de esta institución y cuando la Cruz Roja fue nombrada institución auxiliar de la Sanidad del Ejército Nacional.

5. El historiador Colin Jones (1989) examinó los convenios que Hijas de la Caridad tuvo con 161 hospitales de la provincia en Francia y 4 hospitales en París, todos ellos documentos notariales extensos en los que se incluyen de veinte a treinta cláusulas que intentaban regular los derechos y los deberes desde el siglo XVII hasta el XIX. Lo que encontró en estos documentos fue una constante repetición, con algunos pequeños cambios y diferencias. Los mayores cambios los localizó después de la Revolución francesa, cuando trataron de restringir las funciones de las hermanas en la actividad del cuidado de los enfermos. Pero luego los contratos se volvieron a estandarizar. La naturaleza pública de estos acuerdos tenía una orientación más pragmática y material que espiritual y estaba relacionada con las rutinas y procedimientos de los hospitales, y no tanto con ideales. Los aspectos recurrentes fueron el número de hermanas requeridas en las instituciones, el monto de la remuneración y de los viajes, la dotación para la primera instalación, el manejo de las hermanas cuando se enfermaban y la delimitación de las actividades de las hermanas en cada establecimiento. Habría que señalar que la normalización de los contratos llevó a cierta uniformidad en la administración de las instituciones que proveían las hermanas de estas congregaciones femeninas de vida activa.

6. Carta de la hermana Gertrudis a la reverenda madre Du Calvaire, Bogotá, 16 de enero de 1877, ACHCDPB. 
considerable de soldados enfermos y le pregunta, como representante del Poder Ejecutivo, si podría trasladar hermanas de la Caridad a esta ciudad. ${ }^{7}$ En septiembre de 1900, el general Pinzón envió una carta, en nombre del Ministerio de Guerra, a la madre superiora de la Congregación para hacerle la petición de cuatro hermanas que pudieran prestar el servicio en la recién fundada ambulancia en la Costa Atlántica y le solicita que se ponga en contacto con el director de la misma, el doctor José Joaquín Serrano, para los acuerdos correspondientes. $^{8}$

Para el Estado colombiano esta colaboración formal de atención humanitaria a los heridos y enfermos en los campos de batalla era un hecho novedoso. Hasta ese momento no había existido lo que se podría llamar una atención humanitaria neutral e imparcial en los conflictos bélicos. Sí algunos recursos voluntarios para la atención de heridos y enfermos, pero con apenas una organización parcial por parte de cada bando. Por el contrario, para la congregación no era un hecho novedoso, pues la comunidad religiosa había participado ofreciendo estos servicios en la guerra franco-prusiana en 1870, cuando por primera vez se intentó cumplir con los acuerdos iniciales del primer Convenio de Ginebra, de 1864, que daría origen a la Cruz Roja Internacional (Hutchinson,1996). En el foIleto Las Dominicas de la Presentación en las guerras civiles de Colombia, 18761899 (Charria Angulo, 1993), se afirma que algunas de las hermanas que llegaron al comienzo a Colombia habían estado cerca de los heridos de la guerra europea mencionada. ${ }^{9}$ Hecho factible, dado que en esta guerra se vio por primera vez el trabajo voluntario e independiente de mujeres en varios campos, entre ellos la atención de los heridos y enfermos (Gill, 2009; Denis Maher, 1999).

Diferente fue el momento de la guerra colombo-peruana en $1933,{ }^{10}$ cuando la atención humanitaria se había consolidado y definido mundialmente, sobre todo después de la Primera Guerra Mundial. Para esta guerra, el director de Sanidad del Ejército, J. Esguerra López, en nombre del Ministerio de Guerra de la República de Colombia, hizo la solicitud expresa, directa y formal a la congregación y le presentó una propuesta de contrato para que administrara los hospitales militares temporales: María Teresa, en el río de Caucaya; Nave, en Tarapacá, sobre el río Putumayo; La Tagua, a orillas del río Caquetá; y La Primavera,

7. Carta de la hermana Octavia a la reverenda madre Du Calvaire, Medellín, 13 de mayo de 1877, ACHCDPB.

8. Carta del general Próspero Pinzón a la madre superiora de las Hermanas de la Caridad, Bogotá, 28 de septiembre de 1900. Carpeta de las ambulancias, ACHCDPB.

9. El historiador francés Jacques Léonard (1977) ha resaltado la formación y las prácticas médicas de las congregaciones femeninas de vida activa francesas.

10. La guerra colombo-peruana fue un enfrentamiento entre los dos países por un área en la frontera amazónica, en la que Colombia perdió una extensión de su territorio en esta zona. El primer incidente ocurrió en septiembre de 1932, cuando en la ciudad de Leticia varios peruanos desarmaron y arrestaron a los policías colombianos que había en la ciudad. Los entonces presidentes de Perú y Colombia en un inicio desestimaron el incidente y pensaron que se trataba de un episodio doméstico de cada país. Sin embargo, este acontecimiento llevó a discutir de nuevo el Tratado Salomón-Lozano, firmado en 1922, que fijaba los límites fronterizos entre los dos países. Las dos partes no llegaron a ningún acuerdo para ratificarlo e iniciaron enfrentamientos bélicos en 1933. Al año siguiente, en 1934, se firmó el armisticio. 
cerca del río Orteguaza, creados para atender a los soldados heridos en los combates. ${ }^{11}$ Esta propuesta planteaba que las hermanas estarían encargadas de la inspección y dirección de los hospitales militares del Ejército en lo relativo al buen orden, economía y moralidad. En cada hospital habría tres hermanas y el Ejército les pagaría 30 pesos mensuales, además de las prerrogativas concedidas a los miembros del Ejército en la región, como alimentación, alojamiento, pasaportes, atención médica y licencia en caso de enfermedad. Las hermanas tendrían personal doméstico subordinado a ellas y para los asuntos científicos se deberían entender con los médicos encargados de los hospitales. El Gobierno también se comprometía a sostener un capellán en los hospitales. Después de estudiar el acuerdo, la superiora provincial, la hermana Marie Agnes, firmó el contrato con estas condiciones por seis meses susceptibles de prórroga si fuese necesario, con la Dirección de Sanidad del Ejército del Ministerio de Guerra. ${ }^{12}$

En el Archivo de la Congregación de las Hermanas de la Caridad Dominicas de la Presentación se encuentran diferentes escritos acerca de la actividad que las hermanas realizaron durante las guerras civiles colombianas desde la de 1876 hasta la de los Mil Días (entre 1899 y 1902), y en la guerra colombo-peruana de 1933. Los escritos sobre la guerra civil de 1876 son las cartas-diarios enviadas a la madre superiora de Tours, donde se relatan sus experiencias, que contrastan con de las de la guerra civil de los Mil Días, que fueron redactadas por algunas hermanas que participaron en ella y en las que se narran sus remembranzas, posiblemente transcurrido un corto tiempo tras las vivencias.

Las reminiscencias son diez: cuatro en francés y las otras seis en español, con diferentes extensiones, de tres a siete páginas, todas escritas a mano. Nueve de ellas nos relatan las experiencias de la parte central y oriental del país - Cundinamarca, Boyacá y Santander Y Norte de Santander-, y una trata sobre la costa atlántica colombiana. De cuatro de las narraciones sabemos el nombre de las autoras; las demás no se encuentran firmadas. Las hermanas Ana Josefina y Clementina escribieron sus relatos en español, la primera sobre las acciones de las ambulancias en Cundinamarca, Boyacá y Santander y la segunda solo sobre Santander. Las Hermanas Euphrasia y Helena escribieron en francés sobre las actividades del cuidado de los enfermos y heridos, la primera sobre Cundinamarca y la segunda sobre La Guajira. Estos textos sorprenden porque en la comunidad religiosa no era una prioridad escribir reminiscencias, sino ejercer la acción; quizá una de las razones para redactarlas fue el impacto tan fuerte que causó en ellas esta experiencia, a lo que podría sumarse la exigencia en trabajo y las múltiples incomodidades que estas mujeres tuvieron que soportar durante el tiempo que prestaron estos servicios, además de la necesidad de informar a su superiora de sus actividades y desplazamientos (Castro Carvajal, 2014b).

11. Carta de J. Esguerra López, director de Sanidad del Ejército, a la reverenda madre provincial de la Presentación, Bogotá, 2 de octubre de 1933. Carpeta de las ambulancias, ACHCDPB.

12. «Proyecto de contrato para los hospitales de la frontera del sur entre el Ministerio de Guerra y la reverenda madre provincial de las Hermanas de la Presentación». Carpeta de las ambulancias, ACHCDPB. 
En el caso de la guerra colombo-peruana, existen cartas dirigidas a la superiora provincial en las que se informa sobre las actividades en los hospitales militares de Caucayá, La Tagua, Tarapacá y La Primavera, creados en el sur del país, en la zona selvática del Amazonas, para atender a los soldados heridos en conflicto, siguiendo la práctica habitual dentro de la comunidad religiosa de informar sobre sus misiones y labores.

No es de extrañar que partes de los relatos tengan la perspectiva de las mujeres religiosas, pues se trató sin duda de experiencias vívidas que les supusieron sacrificios y exponerse en ciertos momentos a peligros extremos para ellas, sobre todo los de las guerras civiles (Castro Carvajal, 2014b). Los asumimos como memorias, entendidas como una exposición de hechos, datos o motivos referentes a determinados asuntos, y como tantas otras que existen sobre las guerras civiles colombianas de políticos y militares que participaron de alguna forma en estos conflictos bélicos (Deas, 2001; Escobar Guzmán, 2005). Los escritos de las hermanas contienen descripciones sobre diferentes aspectos de las Ilamadas ambulancias y los hospitales militares, como también detalles de los combates, de las dificultades en los trayectos recorridos y algunas narraciones sobre el mundo rural colombiano y celebraciones religiosas. Estos relatos coinciden con muchos de los textos sobre las guerras civiles, a partir de los cuales los historiadores han hecho las caracterizaciones y análisis de estos conflictos, lo que nos permite confiar en su verosimilitud (Sánchez y Peñaranda, 1986; Jaramillo, 1991).

Trataremos de exponer, entonces, por una parte, la forma en que la Congregación de las Hermanas de la Caridad de la Presentación realizó la atención humanitaria neutral en las guerras civiles colombianas desde 1876, a partir de sus conocimientos y prácticas sobre el auxilio de heridos y el cuidado de los enfermos en los enfrentamientos bélicos; $y$, por otra parte, la importancia de la participación de estas mujeres religiosas o hermanas como un aporte relevante para la introducción de la práctica de la atención humanitaria neutral, sin partido político, a pesar de las conflagraciones partidistas recurrentes durante el siglo XIX colombiano, y también como una contribución significativa para la formalización e institucionalización de la ayuda humanitaria en la guerra colomboperuana de 1933.

\section{Características de las ambulancias}

Las llamadas «ambulancias», como hemos dicho, eran campos provisionales de atención humanitaria para atender a los heridos y los enfermos en los enfrentamientos. Durante las guerras civiles colombianas de la segunda mitad del siglo XIX eran organizadas por los dos bandos enfrentados en el conflicto (que apoyaban las causas conservadoras o las liberales) o por los distintos gobiernos.

Para la solicitud del servicio de las hermanas, los generales, los presidentes o los secretarios de los gobiernos se dirigían directamente a la superiora general cuando se encontraban en Bogotá o cerca de la capital, o a la hermana que 
estuviese como superiora de las obras en las diferentes localidades del país. Las hermanas superioras decidían con cuántas podían colaborar según el número de mujeres religiosas que hubiese en los distintos establecimientos y las obligaciones que tuvieran en ese momento, pero habitualmente iban tres o cuatro de ellas, siguiendo el patrón de las fundaciones de nuevas casas en las diferentes partes de país. Para el caso de la guerra civil de los Mil Días, como la mayoría de las escuelas que tenía la Congregación cerraron y era muy necesaria la colaboración, muchas de las hermanas que trabajaban en la educación participaron junto con las mujeres religiosas que propiamente estaban dedicadas a la administración de hospitales y al cuidado de los enfermos. ${ }^{13}$ Fue en esta guerra cuando más hermanas participaron en las distintas ambulancias que se crearon en el territorio colombiano.

En general, las ambulancias se localizaban cerca de los lugares de combate donde se podía ofrecer algún tipo de sitio cubierto para atender a los heridos, o en los hospitales existentes cuando los enfrentamientos se desarrollaban cerca de los centros urbanos que tenían estas instituciones de salud. Algunas descripciones de las hermanas permiten conocer los puntos y recintos en que se establecían. En la guerra civil de 1876 la ambulancia de Guayabal se organizó en veinte casas cubiertas de paja sin ventanas, como eran las de la población. Acogieron a quinientos heridos: en unas casas ubicaban a los soldados, en otras, a los oficiales; tenían muy pocas camas, que eran de tablas duras, así que a la mayoría de los heridos los tenían que acomodar en el suelo (En el país del oro y de las esmeraldas, 1960). Durante la famosa batalla de Palonegro, se llegaron a instalar cuatro sitios alrededor de Bucaramanga, fuera del Hospital de San Juan de Dios de la ciudad, para lograr atender a todos los heridos y enfermos. Estos sitios llamados «hospitales» no eran más que casas grandes que sus dueños cedían y que se acondicionaban mínimamente para ofrecer la atención humanitaria.

La que se llamó ambulancia en la guerra colombo-peruana fue organizada por la Cruz Roja Nacional, por exigencia del Gobierno nacional, como parte de sus funciones, y la institución se hizo cargo del Hospital Militar de Potosí, a orillas del río Orteguaza. Los otros sitios de atención humanitaria fueron los hospitales militares provisionales establecidos en la frontera sur del país en el Amazonas por la Dirección de Sanidad del Ministerio de Guerra. Todos estos lugares de atención a los soldados que participaban en el conflicto internacional se ubicaban en destacamentos militares. Los establecimientos funcionaban en casas de madera construidas sobre pilotes de 1 metro de altura, debido a la humedad o previniendo inundaciones, y los pisos y paredes eran hechos con palma y los techos, con paja. ${ }^{14}$ El mejor dotado, según lo describen las hermanas, era el

13. Es necesario resaltar nuevamente que todas las hermanas de esta congregación tenían un mínimo conocimiento de los primeros auxilios, recibido como parte de su formación, lo que les permitía ayudar a atender a los heridos y a los enfermos.

14. Carta de la hermana Cecilia María a nuestra muy digna madre María Inés, Caucayá, 12 de marzo de 1933. Carpeta de las ambulancias, ACHCDPB. 
hospital militar de La Primavera. ${ }^{15}$ Dice el brigadier general José Jaime Rodríguez que en el hospital de Potosí:

[...] se instalaron enfermerías bien dispuestas, con salas de esterilización y de cirugía, laboratorios clínicos para bacteriología y entomología, salas de curaciones y lavados, protegidas, y máquinas de lavar y planchar que mucha ayuda dispensaron a las tropas [...]. Esta infraestructura sentó bases para que, al terminar el conflicto, quedaran en estas zonas incorporadas a los servicios de salud del país, con gran provecho para las poblaciones indígenas y blancas de la región (Rodríguez, 1994: 117).

\subsection{Los recursos para las ambulancias}

Los recursos para conformar las ambulancias, en el caso de las guerras civiles colombianas, dependían de aquellos que tuviera el bando que los solicitaba. En cuanto a la guerra de los Mil Días, como el bando conservador estaba en ese momento en el Gobierno, los recursos provenían del Ministerio de Guerra y posiblemente eran más abundantes que los de los liberales, a menudo escasos o difíciles de conseguir, como lo menciona Carlos Eduardo Jaramillo (1991) en su libro sobre esta guerra civil, y como lo relata la hermana que escribió en 1899 el texto titulado La primera ambulancia de la Revolución. ${ }^{16}$

Los recursos para las ambulancias se destinaban básicamente a pagar los medios de transporte de los miembros de las mismas (que solían consistir en unas cuantas bestias), a alimentación y a lograr una buena dotación para la misión (sobre todo de drogas, gasas, frazadas, fósforos, jabón y agua, que era lo que más faltaba, elementos esenciales para hacer las curaciones y mantener la higiene de las ambulancias). En ningún relato de las hermanas o de los militares durante las guerras civiles colombianas de la segunda mitad del siglo XIX se menciona remuneración por esta labor; todos los miembros de las ambulancias realizaban su trabajo de forma voluntaria; las hermanas solicitaban únicamente una hamaca, un delantal y un toldillo al Ministerio de Guerra como dotación. A diferencia de la colaboración en el conflicto internacional de 1933, donde sabemos que las mujeres religiosas y los boticarios recibieron, al menos, una pequeña retribución por sus servicios, como ya hemos precisado. En la guerra colombo-peruana fue el Gobierno nacional el que proporcionó el dinero para el funcionamiento de los hospitales militares temporales. La Cruz Roja Colombiana apeló a la solidaridad nacional para conseguir recursos destinados a la ambulancia organizada por dicha institución (Bejarano, 1934).

15. Carta de la hermana María Benjamín a la muy querida y reverenda madre, abril de 1934. Carpeta de las ambulancias, ACHCDPB.

16. «Primera ambulancia de la Revolución», Florida, octubre de 1899. Carpeta de las ambulancias, ACHCDPB. 


\subsection{Conformación de las ambulancias}

Todas las ambulancias de las guerras civiles estaban conformadas por médicos, algunos de ellos cirujanos; por los llamados practicantes, que eran estudiantes de Medicina o enfermeros; por capellanes, y por las hermanas. El número de cada uno de estos grupos lo determinaban las necesidades de atención a los heridos y los enfermos que cada combate dejaba: se establecía el tamaño antes de los enfrentamientos y en algunas ocasiones estas estimaciones resultaban erradas, por lo que tenían que solicitarse refuerzos después del hecho bélico. Sin embargo, el tamaño de las ambulancias nunca fue grande, y el trabajo que exigían estos servicios fue bastante exigente para todos sus miembros. La ambulancia más grande de las guerras civiles que reportan las hermanas fue la que se formó en Bucaramanga y sus alrededores después de la famosa batalla de Palonegro en la guerra civil de los Mil Días, que en todos los escritos sobre las guerras civiles se coincide en que fue el combate más largo y sangriento y que cambió la forma de enfrentamiento bélico, de los choques entre los dos ejércitos a las emboscadas de las guerrillas. Algunos estiman que tras dos semanas de enfrentamientos perecieron más de 2.000 combatientes y quedaron tendidos en el campo de batalla centenares de heridos; el doctor Putnam, jefe de la ambulancia del ejército del norte de la guerra civil de los Mil Días, registró 800 miembros amputados y no menos de 16.000 heridos. ${ }^{17}$ En ese momento llegaron a estar prestando servicio 40 hermanas que vinieron de diferentes partes del país para atender los heridos y enfermos que quedaron después del enfrentamiento, cuando la Congregación tenía 62 mujeres religiosas francesas y 265 colombianas. Fue sin duda un momento de gran demanda para la comunidad, si se tiene en cuenta además que en la mayoría de las ambulancias participaron tres o cuatro mujeres religiosas.

La ambulancia de la Cruz Roja en la guerra colombo-peruana estuvo conformada por tres médicos, dos practicantes, dos enfermeras y un capellán. De igual forma, los hospitales militares temporales del Ministerio de Guerra tenían médicos, soldados enfermeros, capellanes y hermanas de la Caridad, que cumplían la labor de administración de los establecimientos junto con el cuidado de los soldados enfermos y heridos. ${ }^{18}$ En el hospital militar de La Tagua, en 1934, las hermanas dan cuenta de 49 enfermeros, 15 trabajadores y 7 empleados. ${ }^{19}$

Los cuadros adjuntos permiten visualizar el esfuerzo realizado en torno a la organización de las ambulancias durante las guerras civiles colombianas y de los hospitales militares de la guerra colombo-peruana.

17. «Recuerdo, por el doctor Putnam». Carpeta de las ambulancias, ACHCDPB.

18. «Acta de Instalación del Hospital Militar Caucayá, llamado María Teresa en honor de la esposa del presidente Enrique Olaya Herrera». Carpeta de las ambulancias, ACHCDPB. En 1933 este hospital contó con el servicio de cuatro hermanas: la reverenda madre María Cecilia y las hermanas Marta Rosa, Ana Cecilia y Elisa María; y el de Tagua contó en 1934 con tres hermanas: Francisco de Sales, San Benedicta e Irene María.

19. Carta de las hermanas a nuestra muy digna y querida madre, Tagua, 16 de abril de 1934. Carpeta de las ambulancias, ACHCDPB. 
Cuadro 1. Las ambulancias de las guerras civiles colombianas en las que participó la Congregación de las Hermanas de la Caridad de la Presentación (1876-1901).

\begin{tabular}{|c|c|}
\hline Año & Lugar de las ambulancias \\
\hline 1876 & $\begin{array}{l}\text { Bogotá } \\
\text { Mariquita } \\
\text { Guayabal }\end{array}$ \\
\hline 1877 & $\begin{array}{l}\text { Medellín } \\
\text { Manizales }\end{array}$ \\
\hline 1896 & $\begin{array}{c}\text { Riohacha } \\
\text { Barranquilla } \\
\text { Cartagena }\end{array}$ \\
\hline 1899 & $\begin{array}{l}\text { Anolaima } \\
\text { Fusagasugá } \\
\text { Girardot } \\
\text { Flandes } \\
\text { Sogamoso } \\
\text { Soatá } \\
\text { Cocuy }\end{array}$ \\
\hline $1899-1900$ & $\begin{array}{c}\text { Mesa de los Santos } \\
\text { Piedecuesta } \\
\text { Floridablanca } \\
\text { Bucaramanga } \\
\text { Palonegro } \\
\text { Vélez } \\
\text { Cúcuta }\end{array}$ \\
\hline 1901 & $\begin{array}{c}\text { Chiquinquirá } \\
\text { Cocuy } \\
\text { Chita } \\
\text { Llanos del Casanare }\end{array}$ \\
\hline 1901 & $\begin{array}{l}\text { Simijaca } \\
\text { Briceño }\end{array}$ \\
\hline
\end{tabular}

Fuente: Gaitán Cruz (1999: 106). 
Cuadro 2. Los hospitales militares de la guerra colombo-peruana en los que participó la Congregación de las Hermanas de la Caridad de la Presentación (1933-1934).

\begin{tabular}{|c|c|c|}
\hline Año & Lugar de los hospitales militares & Núm. de hermanas \\
\hline \multirow{2}{*}{1933} & Caucayá & 4 \\
\hline \multirow{3}{*}{1934} & La Tagua & 3 \\
& Tarapacá - Nave Hospital & 3 \\
& La Primavera & 3 \\
\hline
\end{tabular}

Fuente: Elaboración propia a partir de documentación del Archivo de la Congregación de las Hermanas de la Caridad Dominicas de la Presentación. Provincia de Bogotá.

\subsection{La atención a los heridos y a los enfermos}

El objetivo principal de las ambulancias era atender a heridos y enfermos después de los enfrentamientos. Sin embargo, debido a las malas condiciones en que quedaban muchos de los soldados, a lo que se sumaba la escasez de los recursos quirúrgicos y de los tratamientos médicos posibles, la mayoría de los heridos fallecían, lo que exigía a los miembros de las ambulancias, principalmente a los capellanes y a las hermanas, ayudarlos y acompañarlos a morir con tranquilidad y de forma cristiana. «Ninguno de los asistidos por las Hermanas murió sin haber recibido los últimos Sacramentos" (En el país del oro y de las esmeraldas, 1960: s. p.). Cuando los muertos fueron numerosos, colaborar a enterrarlos de la mejor forma fue otra tarea de las ambulancias, no solo por cumplir con la moral cristiana sino también por razones de salud pública: para evitar que alguna epidemia se propagara. Pero hubo momentos en que eran tantos los muertos que había que tomar otras medidas, como lo relata la hermana que describe el combate de Puerto del Sol del 13 de diciembre de 1899:

El combate terminó y finalizó a las cinco de la tarde, la villa estaba en calma. Al otro día hemos recorrido el campo de batalla [...]. Los muertos han sido arrumados los unos sobre los otros, para quemar los cuerpos. Qué cosa horrible. Un olor fétido se había expandido en toda la ciudad y hasta el hospital: muchos días después hemos encontrado también muchos muertos comidos por los cuervos. ${ }^{20}$

Los tratamientos que más se mencionan en los relatos de las hermanas eran las curaciones de heridas hechas por armas de fuego y armas blancas, particularmente machetes. Muchas veces la única opción era la amputación de al-

20. «Combate de la Puerta del Sol», 13 de diciembre de 1899. Carpeta de las ambulancias, ACHCDPB. 
gún miembro (brazo, mano, pierna), intervención que era bastante peligrosa por las condiciones higiénicas de las ambulancias, sobre todo en las más improvisadas. El uso de las compresas para las hemorragias fue uno de los métodos más mencionados, solo que a veces era limitada, por la escasez de gasa o vendas, por lo que a menudo se sustituían por jirones de sábanas que se rasgaban para estos fines. Una de las hermanas relata estos procedimientos: "Las curaciones se hacían en forma muy rudimentaria: con hilas sacadas de trapos viejos, se envolvían unos palitos y con ellos se limpiaba la podredumbre y se sacaban los gusanos [...] una curación duraba horas» (Charria Angulo, 1993: s. p.).

La fiebre amarilla, el tifus y la disentería fueron las enfermedades que más nombran las reminiscencias de las hermanas, y se sabe que algunas de estas mujeres fueron víctimas de contagio y acabaron falleciendo por esta causa. Para estas enfermedades no había sino medicamentos básicos, lo que provocaba que muchos de los combatientes murieran de ellas, sobre todo hombres que habían tenido jornadas largas e intensas, que habían pasado por varios climas extremos, de regiones calientes a zonas de páramo, con alimentación insuficiente. En algunas ocasiones, cuando se juntaba un número considerable de heridos y enfermos y los sitios de reclusión disponibles no eran muy espaciosos, no fue posible separarlos por afecciones, y por lo tanto la propagación de los contagios aumentaba y causaba más estragos que los mismos combates.

Cuando los heridos no ofrecían mayor gravedad y ya habían recibido las curaciones necesarias, se hacía lo posible para enviarlos de inmediato a otros sitios y así evitar los contagios (En el país del oro y de las esmeraldas, 1960). Sin embargo, las epidemias se hacían difíciles de controlar por la permanente fuga de convalecientes, que muchas veces se escapaban de los hospitales en el momento en que su enfermedad presentaba mayores posibilidades de contagio (Jaramillo, 1991). En una comunicación del síndico del Hospital de Bucaramanga al inspector general del Ejército el 11 de agosto de 1900 se constata la dificultad de mantener el orden en el centro hospitalario y las ambulancias:

Pero es el caso que en primer lugar ese hospital y el de Campo Hermoso carecen por completo de guardia, de modo que los enfermos refutan esos asilos como casas de asistencia, saliéndose todo el día y hasta pernoctando fuera, yendo únicamente allá a tomar los alimentos; y en segundo lugar no hay quien disponga de los soldados ya útiles para llevarlos al servicio, no quién haga a los inválidos las diligencias para el pasaporte, y todo el día se ven estos vagando por las calles de la ciudad y cuando vuelven a los hospitales entran ebrios a cometer toda clase de excesos irrespetando a las pobres Hermanas de la Caridad que son las encargadas de custodiarlos (Jaramillo, 1991: 154).

Durante la guerra colombo-peruana, las hermanas mencionan más el cuidado de soldados enfermos que el de heridos, dado que la mayoría de las muertes fueron causadas por el tifus, el paludismo, el llamado beriberi, la poliomielitis o la pulmonía, más que por lesiones de combate. Además, algunos soldados llegaban muy débiles y desnutridos por falta de alimentación a los hospitales 
militares. ${ }^{21}$ En su relato sobre la guerra, Arturo Arango Uribe menciona algunos de los cuidados: «La hermana Marta Rosa da algunas vueltas, investiga y vuelve al botiquín para regresar con inyecciones, papeletas, cápsulas, todo un mundo de remedios que sus manos hacen más eficaces» (Arango Uribe, 1933: 23). En casi todos los sitios el número de enfermos en los momentos que hubo más fue cercano a ochenta y a los más graves los trataban de evacuar lo más pronto posible; en otras ocasiones oscilaban alrededor de la veintena, pero nunca en las cartas se relatan situaciones de congestión en la atención humanitaria como durante las guerras civiles colombianas. En el hospital militar de La Primavera recibían a los enfermos que enviaban de los otros por estar mejor provisto. Después del combate en Güepí hubo ciento cuarenta enfermos, pero al mes siguiente la cifra se había reducido a cuarenta. ${ }^{22}$

El rol de la congregación en las ambulancias durante las guerras civiles colombianas de la segunda mitad del siglo XIX y en la guerra colombo-peruana fue, en la medida de lo posible, seguir las indicaciones de los jefes para colaborar en la organización de las mismas según las órdenes castrenses, para ayudar a establecer unas mínimas condiciones higiénicas en los sitios temporales, para asistir a los heridos y enfermos con los tratamientos médicos indicados y viables, para brindar comodidades exiguas (como un sitio de reposo, frazadas y comida) y para dar el soporte espiritual cuando la muerte era un hecho cercano y factible. Las hermanas apoyaron las ambulancias y hospitales militares ofreciendo su experiencia en la administración de instituciones de asistencia social y en la atención a los heridos y enfermos, que conocían y que desarrollaban en las distintas misiones en el territorio colombiano, y al mismo tiempo introduciendo el apoyo humanitario neutral en medio de las múltiples dificultades de las guerras civiles colombianas, como veremos en el siguiente apartado.

\section{Las dificultades de la neutralidad en la atención humanitaria de las guerras civiles colombianas de la segunda mitad del siglo XIX}

Uno de los mayores problemas de las primeras ambulancias en las guerras civiles de la segunda mitad del siglo xIX fue la creación del ambiente de confianza entre los dos bandos acerca de la neutralidad de las personas que ofrecían la atención humanitaria. Cuando se pusieron en marcha las primeras ambulancias en las guerras civiles colombianas, la idea de la atención humanitaria neutral no estaba completamente arraigada en el país, y tampoco lo estaba en el resto del mundo. Además, como sabemos, las guerras civiles fueron enfrentamientos entre colombianos que eran simpatizantes y militantes de los partidos políticos, lo que hacía más difícil la comprensión de la imparcialidad y la neutralidad en cual-

21. Carta de la hermana Ana Magdalena a la muy digna madre Juana Margarita, Tarapacá, 22 de junio de 1933. Carpeta de las ambulancias, ACHCDPB.

22. Carta de la hermana María Benjamín a la muy digna y querida madre, 4 de julio y 20 de agosto de 1934. Carpeta de las ambulancias, ACHCDPB. 
quier atención. A diferencia de la guerra colombo-peruana, que fue un enfrentamiento internacional que aglutinó a todos los colombianos en contra de los ciudadanos de otro país, y que de cierta manera incitó el nacionalismo y, por lo tanto, era más fácil entender y respetar el ofrecimiento de una atención organizada y centralizada a los heridos y enfermos de la guerra, además de que el concepto de neutralidad en la atención a estas víctimas ya se encontraba definido.

En las primeras ambulancias en las que participaron miembros de la Congregación de las Hermanas de la Caridad de la Presentación surgieron algunas dudas acerca de su neutralidad. La primera desconfianza provenía de que la congregación pertenecía a la Iglesia católica, y esta institución no había sido imparcial en sus posiciones políticas en Colombia sino que había participado de las disputas y, además, había evidencias de la intervención de algunos sacerdotes católicos en la política y en las guerras civiles, sobre todo en apoyo del partido conservador, como lo han indicado varias investigaciones (Cortés, 1986; Ortiz, 2005). Por lo tanto, la sospecha sobre la neutralidad de la congregación era generalizada, en particular en la primera guerra civil colombiana que le tocó vivir a la comunidad religiosa, que fue la de 1876, la cual tuvo como uno de los principales detonantes precisamente el conflicto con la Iglesia católica acerca del rol y la participación de esta en la educación. Una de las reglas de la comunidad religiosa, como la de las congregaciones religiosas femeninas de vida activa, era la no participación en política. Parece que la congregación mantuvo esta norma desde su llegada, pero ello no evitaba las sospechas sobre su actuación en los conflictos. Empezada la guerra del 1876, las visitas domiciliarias a los enfermos pobres realizadas por la hermana Anthyme fueron objeto de duda y se creía que llevaba mensajes de los conservadores, por lo que la congregación se vio obligada a suspender esta labor hasta que la guerra civil terminara. Las cartas que las hermanas escribían a las superioras de Bogotá y Medellín durante las guerras civiles eran abiertas y a veces no llegaban a su destino porque se desconfiaba de su contenido (En el país del oro y de las esmeraldas, 1960). Resultaba igualmente difícil para la congregación mostrar y convencer de su neutralidad en medio del conflicto, como lo comenta la hermana Octavia en una carta enviada en 1877 a la reverenda madre Du Calvaire:

En Medellín, la política desempeña un gran papel, parece que todo debería referirse a ella. Un día dicen que nosotras somos liberales, al día siguiente [,] que [somos] conservadoras. Para cortar en seco todas estas suposiciones, yo contestaba a todos los que querían conocer nuestra opinión que nuestra política, la nuestra como religiosas [,] era la caridad. Esto produjo buen efecto en los dos partidos, que me dejaron en paz. ¡Bendito sea Dios! ${ }^{23}$

23. Carta de la hermana Octavia a la reverenda madre Du Calvaire, Medellín, 13 de mayo de 1877, ACHCDPB. 
De forma similar la hermana Gertrudis expresaba en carta enviada a la superiora general de Tours:

Siempre en plena guerra estamos respetadas y gozando de la confianza de ambos partidos, porque al principio creían todos que estábamos metidos en política; como tal cosa es contraria a nuestra santa vocación, vieron por experiencia propia que no nos preocupan sino las obras de caridad. ${ }^{24}$

La casa principal de la congregación en Bogotá también fue objeto de sospecha durante la guerra civil de los Mil Días, dado que en ese momento se estaba construyendo la iglesia y vivían allí dos ingenieros, uno de ellos hermano del médico y político doctor Juan Evangelista, quien era buscado por el Gobierno como revolucionario, por lo que varias veces se vio allanada y en cada una de las clases del Colegio Sans Façon pusieron un soldado. Según el escrito de la hermana San Camilo de la Cruz a partir de los relatos que había escuchado en la congregación, la comunidad religiosa tomó algunas medidas: «Para evitar las rondas la Hermana Gertrudis resolvió izar la bandera francesa y poner un aviso en la puerta de la carrilera que decía: "Propiedad Extranjera" y así nos libramos de más sustos y requisas". ${ }^{25}$

Estas sospechas sobre la congregación posiblemente se trasladaban a las ambulancias, lo que hacía difícil, a veces, que vieran a sus miembros como personas neutrales en los conflictos. Como las ambulancias en las guerras civiles eran organizadas por cada uno de los dos bandos, se consideraba que sus miembros pertenecían a determinado partido político. Cuando ganaba el bando opuesto a los organizadores de las ambulancias, era difícil mantener el dominio y el control sobre los auxiliares, que se veían en la obligación de huir para no ser apresados. En la carta que envía la hermana Saint Iries a la reverenda madre Du Calvaire desde Manizales en 1877 se constata esta situación:

El 13 de abril tuvo lugar la sangrienta lucha cuyo resultado fue el triunfo del partido liberal [...]. Acompañadas por el médico jefe de las ambulancias, nos presentamos tres Hermanas al general de las tropas liberales para implorarle su protección para el hospital y auxilio para los heridos [...]. La guardia que envió el general para defender la entrada del hospital prestó muy buen servicio, pero había que cambiar todo el personal de la casa [...] [y] como nuestros antiguos enfermeros eran conservadores todos huyeron y los que quedaron no saben manejar [a] los enfer$\operatorname{mos}^{26}$

Sin embargo, el Gobierno recién establecido en esa ciudad envió una carta a la hermana Octavia a Medellín para solicitarle que continuara el contrato que tenían con el anterior gobierno, de manera que las hermanas pudieran seguir

24. Carta de la hermana Pauline a la reverenda madre Du Calvaire, Bogotá, 9 de noviembre de 1876, ACHCDPB.

25. Madre San Camilo de la Cruz, «Retazos de historia de la Presentación, 1896-1912». Carpeta de las ambulancias, ACHCDPB.

26. Carta de la hermana Saint Iries a la reverenda madre Du Calvaire, Manizales, 2 de mayo de 1877, ACHCDPB. 
atendiendo a los numerosos enfermos y heridos de los dos ejércitos beligerantes reunidos en el Hospital de Manizales. Para la Congregación esta comunicación era una prueba de confianza y una garantía de protección para continuar su labor humanitaria. ${ }^{27}$

Asimismo se dudaba de que se atendiera de igual forma a los heridos y los enfermos de ambos bandos: cuando a finales de 1899 el partido liberal logró una victoria transitoria en Bucaramanga, los jefes militares entraron al hospital de la ciudad a preguntar a los pacientes de su partido si habían sido bien tratados y asegurarse de que las hermanas no hacían ninguna distinción en la atención humanitaria. ${ }^{28}$

Otro de los peligros para el funcionamiento de las ambulancias fue la ausencia de claridad en los símbolos que significaban la neutralidad en las acciones bélicas. La bandera blanca tenía varios significados: era la señal para armisticios o sitios neutros donde los generales de ambos sitios podían discutir e incluso llegar a negociaciones de paz, pero también era la indicación de rendimiento o capitulación. Este hecho creaba confusión y ponía de manifiesto que no había una forma clara de expresar la atención humanitaria para que todos los involucrados en el conflicto la entendieran (En el país del oro y de las esmeraldas, 1960). Para los miembros de las ambulancias, circular cerca de los combates no era seguro en todos los casos; la bandera blanca no siempre era respetada, porque se sospechaba de su uso y, además, en algunas ocasiones los miembros quedaban en medio del fuego cruzado, como sucedió en el Hospital de San Juan de Dios de Bucaramanga el 13 de diciembre de 1899: se inició un combate en la ciudad, el capellán dio la orden de poner banderas blancas en el hospital, una en la puerta de entrada y la segunda en los patios de las hermanas que daban al frente de la sacristía; cuando la hermana Pauline junto con un enfermo salieron a ponerlas, una bala golpeó el sombrero del convaleciente y otras cayeron cerca de la hermana sin hacerles ningún mal. ${ }^{29}$ De igual manera en Cúcuta la hermana Clementina relata el incidente en el hospital:

Las Hermanas con los enfermos y enfermas que había, teníamos que andar por algunos puntos agachados, pues hasta en las salas caían balas. A la Hermana Ana [,] que era la de la despensa, casi la matan [,] pues pasando por la despensa para la cocina, una bala le rompió la corneta a pesar de ir un poco agachada. ${ }^{30}$

Esta falta de especificación sobre los símbolos, sumada a que a veces tampoco se sabía exactamente quiénes eran los encargados de mostrar las credenciales acordadas, hacía las labores, para las personas imparciales, más difíciles de lo que habitualmente eran. Por ejemplo, en la guerra civil de 1876, entre Hon-

27. Carta de la hermana Octavia a la reverenda madre Du Calvaire, Medellín, 13 de mayo de 1877, ACHCDPB.

28. "Combate de la Puerta del Sol», 13 de diciembre de 1899. Carpeta de las ambulancias, ACHCDPB.

29. Ídem.

30. Apuntes de la hermana Clementina, 1899. Carpeta de las ambulancias, ACHCDPB. 
da y Mariquita se instaló un ejército que no dejaba pasar a nadie porque se habían reanudado las hostilidades; se necesitaba que algunos soldados ya curados se fueran de Guayabal a Bogotá para evitar que se quedaran en la cárcel de Honda convertida en el hospital de los enfermos de fiebre amarilla y no había manera de que los médicos de las ambulancias autorizados para entregar los pasaportes pudieran pasar (En el país del oro y de las esmeraldas, 1960). La hermana Ana Josefina relata que en la mañana del 8 de febrero de 1901 empezó un combate reñido en Sogamoso que duró todo el día; hacia las tres de la tarde ellas decidieron salir a recoger a los heridos, cuando «todavía se encontraban los furiosos macheteros y los tiradores, a pesar de todo fuimos respetadas y logramos favorecer a uno de los vencidos que eran ultrajados por el enemigo». ${ }^{31}$ La hermana Clementina narra otro incidente: cuando, después de la batalla de Palonegro, la madre, dos hermanas y dos enfermeros salieron con una bandera blanca para enterrar a un muerto y recibieron una descarga, por lo que tuvieron que darle sepultura en el solar del Hospital de San Juan de Dios de Bucaramanga. ${ }^{32}$

Otro de los problemas fue conseguir los recursos materiales cuando se conformaban las ambulancias, o cuando estos se terminaban en plena prestación de los servicios, como lo muestra el relato titulado «Primera ambulancia de la Revolución», de octubre de $1899 .{ }^{33}$ En ocasiones la colaboración provino de algunas señoras, en particular cuando se trataba de alimentación, ropa, sábanas o alojamiento para los miembros de las ambulancias y de los enfermos (Jaramillo, 1995). El riesgo que corrían las personas al apoyar a las ambulancias de cualquier bando era exponerse a ser atacadas por el partido opuesto; por esta razón la mayoría de las ayudas se hacían a escondidas, con mucho sigilo en las noches, y se enviaba a sirvientes completamente cubiertos o asegurándose de que sus colaboraciones no entrañarían ningún peligro.

Una dificultad más para ejercer la atención humanitaria fue que los heridos de los dos bandos en conflicto en las guerras civiles no querían ser atendidos en el mismo sitio y exigieron a los miembros de las ambulancias que se dividieran para auxiliar a las víctimas y se ubicaran en poblaciones diferentes, como sucedió en la guerra de 1876:

Los liberales no quieren enviar sus heridos a Mariquita sino a Guayabal. Los de los conservadores empiezan a pasar sobre camillas improvisadas, rumbo a Mariquita, donde no les faltará oficio a Madre Pauline, Hermana Saint Clet y Hermana Marie Françoise. Al día siguiente, Madre Marie Gertrudis, Hermana Aldric y Hermana siguen a Guayabal. Asimismo se dividen los médicos y los dos capellanes, el doctor Herrera va a Guayabal, mientras que el doctor Escobar se queda en Mariquita (En el país del oro y de las esmeraldas, 1960: s. p.).

La participación de las hermanas en las ambulancias durante las guerras civiles del siglo XIX atendiendo a los heridos y enfermos mostró la posibilidad de

31. Hermana Ana Josefina, datos sobre la guerra de los Mil Días. Carpeta de las ambulancias, ACHCDPB.

32. Apuntes de la hermana Clementina. Carpeta de las ambulancias, ACHCDPB.

33. «Primera ambulancia de la Revolución», Florida, octubre de 1899. Carpeta de las ambulancias, ACHCDPB. 
una atención profesional neutral que generó confianza en el contexto de las diversas y complejas dificultades de unos conflictos bipardistas viscerales, y fue reconocida por los distintos partidos políticos y gobiernos; y, por supuesto, para algunos heridos supuso la salvación de sus vidas. Y al mismo tiempo supuso la introducción de los primeros esbozos de la práctica de la atención humanitaria imparcial, justa y equilibrada para ambos bandos en medio de los peligros, la escasez y los obstáculos en que se ofrecía durante las guerras civiles. Y será una experiencia y conocimiento que se percibe en el desenvolvimiento de la atención humanitaria en la guerra colombo-peruana, donde las mujeres religiosas tendrán un rol definido (figura 1).

Figura 1. Hermanas de la Caridad de la Presentación en la atención humanitaria de la guerra colombo-peruana, enero de 1933.

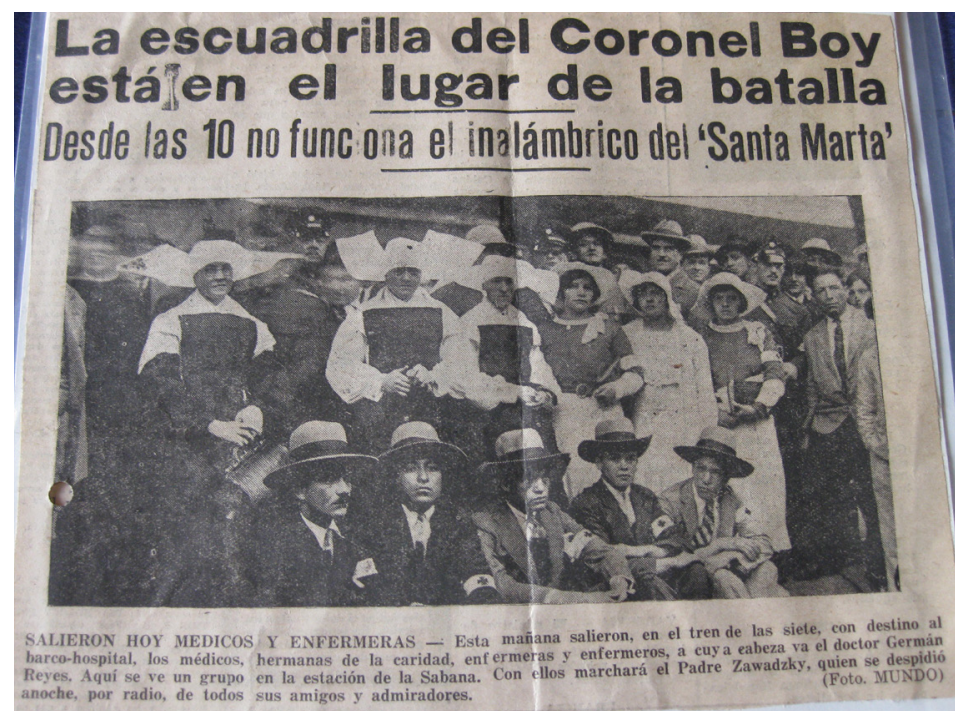

Fuente: Archivo de la Congregación de las Hermanas de la Caridad Dominicas de la Presentación. Provincia de Bogotá.

\section{A modo de conclusión}

Para la Congregación de las Hermanas de la Caridad de la Presentación, la participación de sus miembros en las ambulancias, particularmente en las de las guerras civiles, significó fortalecer los vínculos con el Estado colombiano, que apenas había comenzado con su contratación reciente para la administración de varias instituciones de asistencia social. También les ayudó a demostrar sus capacidades y sus conocimientos en el cuidado de los enfermos y heridos; y, aún más importante, les permitió mostrarse como mujeres religiosas confiables para los distintos gobiernos. 
Igualmente, conllevó grandes sacrificios para quienes colaboraron en ellas; tal vez uno de los más grandes fue el tener que vivir por más tiempo de lo esperado fuera de la comunidad. Las hermanas lo expresaban como «estar en medio del mundo rodeadas cada instante de hombres», ${ }^{34}$ es decir, acompañadas y circundadas de médicos, auxiliares, pero también generales, coroneles, soldados, lo que no les permitía tener sus rutinas habituales de recogimiento de la congregación religiosa. Otra privación que afectó a estas mujeres durante las guerras civiles fue la de estar totalmente incomunicadas entre ellas, como fue el caso de la ambulancia de Manizales en 1877, así como la falta de correspondencia entre las ciudades colombianas o de estas con la casa principal de Tours. Las únicas que mantuvieron cierta comunicación más o menos frecuente con la casa madre de Tours fueron las mujeres religiosas que estaban en Barranquilla. Las mujeres de las comunidades religiosas femeninas de vida activa que intervinieron en la atención a los heridos y enfermos también sufrieron un desgaste físico extremo por las jornadas exigentes, que las privaban de tiempo para el reposo o para comer (lo cual puso en peligro la salud de varias de ellas). Y otras incomodidades, como la carencia de comida, la ausencia de sitios dignos para dormir, los largos viajes por caminos escabrosos y peligrosos, fueron toleradas gracias a la fe, que ofrecía a estas mujeres la perseverancia, serenidad y fuerza que necesitaban en esas circunstancias para salvar los distintos desafíos.

Asimismo, conllevó la muerte de varias de sus hermanas: la hermana San Pablo, en Pamplona; la hermana Bernarda María y la madre Melaine, en Chiquinquirá; la hermana San Pedro y la madre Paz, en El Cocuy, todas contagiadas de tifus; y la hermana San Fermín, en la costa, por una enfermedad pulmonar. Se menciona también que varias hermanas fallecieron en Barranquilla por fiebre amarilla. ${ }^{35}$

De todas maneras, sus servicios fueron agradecidos y apreciados, como lo muestra el telegrama enviado por el secretario de Gobierno el 23 de marzo de 1877 a las hermanas que se encontraban en Medellín: «Os dirijo este telegrama cuyo fin principal es agradeceros haber permitido que las Hermanas se quedaran en Manizales. Sin esto nos sería del todo imposible trabajar eficazmente en la curación de los heridos y la mayor parte de ellos perecería». ${ }^{36} \mathrm{O}$ la carta del doctor Carlos Putnam, jefe de ambulancia, enviada al general del Ejército del Norte el 31 de julio de 1900:

Debo consignar aquí los nombres de mis compañeros, médicos, ayudantes, todos fieles cumplidores de su deber, y el de las admirables Hermanas de la Caridad sin las cuales me habría sido imposible atender a las múltiples ocupaciones que la necesidad impuso en estos días de sacrificio, amarguras y remordimientos de la Patria [...]. Faltaría a un acto de justicia al dejar

34. Carpeta de las ambulancias, ACHCDPB.

35. Madre San Camilo de la Cruz, «Retazos de historia de la Presentación 1896-1912». Carpeta de las ambulancias, ACHCDPB.

36. Carta de la hermana Octavia a la reverenda madre Du Calvaire, Medellín, 13 de mayo de 1877, ACHCDPB. 
de señalar los servicios prestados por [...] y en especial por las Hermanas de la Caridad, respecto a las cuales tengo tanto que decir que se me haría interminable este informe. ${ }^{37}$

Sin duda, la importancia de su fe, sumada a un sentido más racional de la solidaridad, pues estaban convencidas de estar prestando un servicio más que estar ofreciendo dádivas solo a Dios, fue la verdadera orientación de sus actividades. Junto a ellas, la colaboración del servicio profesional, particularmente de los médicos, practicantes y los enfermeros, además de la de los otros miembros seculares en las ambulancias de las guerras civiles colombianas organizadas por los partidos políticos enfrentados, ayudó a construir paulatinamente la atención humanitaria en las guerras civiles colombianas, entendida más como una acción moral (Ignatieff, 1999).

De tal forma, el aporte más significativo de la congregación fue la introducción de la práctica de atención humanitaria neutral en las guerras civiles colombianas del siglo xIX y que será la principal explicación para que el Estado colombiano invite a estas mujeres religiosas a ser parte importante de las ambulancias y hospitales militares en zona selvática del Amazonas durante la guerra colombo-peruana de 1933.

Cuando estalló esta guerra, la Cruz Roja Internacional ya había consolidado las normas de respeto a los sitios y personas que colaboraban en la atención de los heridos y enfermos en los conflictos, y la posibilidad de que existiera una atención humanitaria neutral en medio de los combates bélicos era ya un hecho establecido y acordado entre los bandos enfrentados. Por esta razón la situación de la atención humanitaria en este conflicto internacional es completamente diferente a la de las guerras civiles del siglo XIX, como hemos señalado. En la correspondencia de las hermanas que participaron en la atención humanitaria encontramos solo una carta en que se menciona un momento de tensión en los sitios donde estaban ubicados los hospitales militares antes de uno de los combates más grandes de la guerra, cuando sintieron que uno de los sitios neutrales podía estar en peligro: «Ayer tuvimos la visita de tres aviones peruanos, nos volaron atrevidamente por varios minutos así que inspeccionaron bien el campo siguieron a Güepí y lo bombardearon afortunadamente sin hacer daño ninguno». ${ }^{38}$ La atención humanitaria durante esta guerra se desarrolló sin contratiempos y sin ambivalencias entre los dos países en conflicto, e incluso, según los informes de la Cruz Roja nacional y de los militares, estos hospitales militares se convirtieron en sitios de atención de salud para las personas de las poblaciones cercanas, que anteriormente no habían tenido estos servicios; además, las ambulancias lograron realizar campañas de salud pública en la zona sur selvática de Colombia.

Para la congregación francesa, por lo tanto, la participación en esta guerra fue una decisión acorde, consecuente y responsable con sus principios de ser-

37. Carta del doctor Carlos Putnam a general del Ejército del Norte, Bucaramanga, 31 de julio de 1900. Carpeta de las ambulancias, ACHCDPB.

38. Carta de la hermana Cecilia María a nuestra muy digna madre María Inés, Caucayá, marzo de 1933. Carpeta de las ambulancias, ACHCDPB. 
vicio y de atención, soportados en los conocimientos de organización de instituciones de asistencia social y del cuidado de los enfermos. Y significó también una acción solidaria con un país en el que ya llevaban casi sesenta años haciendo misión, en el que había logrado generar credibilidad en sus oficios y en el que había alcanzado conformar una comunidad religiosa ya con un número mayoritario de mujeres religiosas colombianas (Castro Carvajal, 2014a).

\section{Bibliografía}

Bejarano, Jorge (1934). La obra de la Cruz Roja Nacional. Informe del presidente del Comité Nacional de la Cruz Roja. Bogotá: Tipografía Regina.

Castro Carvajal, Beatriz (2014a). La relación entre la Iglesia católica y el Estado colombiano en la asistencia social c. 1870-1960. Cali: Programa Editorial Universidad del Valle.

Castro CarVajal, Beatriz (2014b). «La escritura de las monjas francesas viajeras en el siglo XIX». Anuario Colombiano de Historia Social y de la Cultura. Bogotá, 41 (1), págs. 91-126.

CoRTÉS, José David (1986). «Clero, política y guerra». En: SÁNCHEZ, Gonzalo y AGUILERA, Mario (comps.). Pasado y presente de la violencia en Colombia. Bogotá: CEREC, págs. 173-193.

DEAS, Malcolm (2001). «Las memorias de los generales. Apuntes para una historiografía de la guerra». En: SÁNCHEZ, Gonzalo y AguILERA, Mario (eds.). Memoria de un país en guerra. Los Mil Días: 1899-1902. Bogotá: Planeta, págs. 125-141.

DENIS MAHER, sister Mary (1991). The bind up the wounds: Catholic sister nurses in the U.S. Civil War. Baton Rouge: Louisiana State University Press.

En el país del oro y de las esmeraldas (1960). Bogotá: Editorial ABC.

EscobAr Guzmán, Brenda (2005). «La guerra de los Mil Días vista a través de las memorias». En: ORTIZ, Luis Javier (coord.). Ganarse el cielo defendiendo la religión. Guerras civiles en Colombia, 1840-1902. Medellín: Universidad Nacional de Colombia, págs. 465-480.

GAITÁN CRUZ, María Cecilia (1999). La enfermería en Colombia. Orígenes de audacia y compromiso. Tunja: Universidad Pedagógica y Tecnológica de Colombia.

Hutchinson, John F. (1996). Champions of charity: war and the rise of the Red Cross. Oxford: Westview Press.

IgNATIEFF, Michael (1999). El honor del guerrero. Guerra étnica y conciencia moderna. Madrid: Taurus.

JARAMILLO, Carlos Eduardo (1991). Los guerrilleros del novecientos. Bogotá: CEREC.

JARAMILLO, Carlos Eduardo (1995). «Mujeres en guerra». En: VELÁsQUEZ TORO, Magdala (dir.). Las mujeres en la historia de Colombia. Tomo II. Bogotá: Norma, págs. 359-386.

JONES, Colin (1989). The charitable imperative. Hospitals and nursing in Ancien Régime and Revolutionary France. Londres: Routledge.

LANGLOIS, Claude (1984). Le catholicisme au féminin: les congrégations françaises a supérieure général au xıxe siècle. París: Éditions du Cerf.

LEONARD, Jacques (1977). «Femmes, religion et médicine. Les religieuses qui soignent, en France au XIxe siècle». Annales ESC, 5, París, págs. 887-907. 
ORTIZ, Luis Javier (coord.) (2005). Ganarse el cielo defendiendo la religión. Guerras civiles en Colombia, 1840-1902. Medellín: Universidad Nacional de Colombia.

RODRíGUEZ, José Jaime (1994). «La fuerza militar colombiana. Los servicios». En: VALENCIA Tovar, Álvaro (dir.). Conflicto amazónico, 1932-1934. Bogotá: Villegas Editores, págs. 107-123.

SÁncheZ, Gonzalo y PeÑaranda, Ricardo (comps.) (1986). Pasado y presente de la violencia en Colombia. Bogotá: CEREC.

Uribe ArAngo, Arturo (1933). 180 días en el frente. Manizales: Tipografía Cervantes.

Fecha de recepción: 6 de enero de 2021

Fecha de aceptación: 9 de marzo de 2021

Fecha de publicación: 30 de junio de 2021 